\title{
E-LEARNING FOR ENTREPRENEURIAL SKILLS IN A DIGITAL BUSINESS ENVIRONMENT
}

\author{
VUCEKOVIC Milos', MEDIC Zorica², MARKOVIC Dusan ${ }^{3}$ \\ ${ }^{1}$ Singidunum University, Belgrade (SERBIA) \\ ${ }^{2}$ Faculty of Business Economics and Entrepreneurship, Belgrade (SERBIA) \\ ${ }^{3}$ Belgrade Business School, Belgrade (SERBIA) \\ Emails:milosvu@gmail.com,zmedic900@gmail.com,markovic.dusanbps@gmail.com
}

\begin{abstract}
Digital skills are becoming an important prerequisite for employment worldwide, but a significant portion of the population still lacks the skills needed to function in a digital business environment. Although young people are often considered "digital connoisseurs", most of them do not actually have enough of these competencies relevant to starting their own entrepreneurial businesses or filling jobs where there is a need for advanced digital skills.

Those with the lowest levels of digital skills would be most affected, as well as those who are least willing to upgrade their skills. Accordingly, it is necessary to promote digital entrepreneurial skills and introduce them into education programs through different forms and levels of education. The main objective of this paper is to explore the possibilities of improving entrepreneurs' competencies through e-learning. In line with this, the authors stressed the need for policymakers to develop a comprehensive and coherent approach to fostering learning and activating digital entrepreneurial skills among young people, while measuring progress towards the goals set, is emphasized. In addition to these, there are many other reasons why digital knowledge must be considered a priority in modern education processes. Accordingly, long-term, and short-term goals and their impact at the level of the individual and organization, as well as at the level of economy and society, have been determined.
\end{abstract}

Keywords: digital entrepreneurial skills, e-learning, e-teaching, employment

JEL: $L 26$

UDC: 005.336.5:004.005.94.004.738.5:339

COBISS.SR-ID: 18170121

\section{Introduction}

The environment for learning has changed rapidly through the applying of new technologies as well as expectations towards professional knowledge in the information age.

Application of various technologies improves learning environment and provides preconditions to transform teaching into learning. The online learning environment is quite different from a traditional classroom, in which one had limited interaction and almost unlimited access to learning resources. E-learning is recognized in many countries as a catalyst for national development. In line with this, the rapid development of e-learning and its modalities geared towards practical skills in business enterprises and leadership competencies is necessary for national self-reliance and development. Delivering learning content anytime, anywhere is a goal that underpins the e-learning paradigm. In addition, based on new technologies, e-learning can support creativity and assist students in developing their 
individual potentials. For this reason, emphasis should be focused on the individual needs of students and personalized training programs. Computer-based educational techniques have been considered as our best hope for individualization [3]. The different levels of interaction and collaboration characteristic of new technologies facilitate the personalization of learning paths. The development and implementation of student-centric technology will bring shift to student-centered pedagogy and the ownership of learning by learners, a quality that is indispensable for fostering creativity. In addition, the goal of a business simulation is of importance for the development of competencies for existing or potential entrepreneurs and leaders. The creative power of the leaders is in the knowledge-intellectual potential, which have become a key factor of productivity, competitiveness and economic success [29]. There is currently a great necessity of a standardized curriculum to be developed and applyed with training and certification of current and future leader [30]. Namely, development of their competencies can increase the ability to apply certain knowledge, skills, and personal, social and methodological skills.

\section{Theoretical Background}

In literature, online learning has been compared to face-to-face learning from different points of view. Thus, Hoben [9] explored the effectiveness of online tools such as discussion boards and chat rooms, while Spatariu [24] addressed evaluating effective online instruction.

Graham [4] assessed the value of online courses in specific fields of study. In particular, the use of virtual worlds to reach remote online learners is creating new opportunities for face-to face engagement and motivation with difficult-to-reach groups. Draves provides a list of reasons why he believes the Internet enhances learning, [5] including such advantages as being able to learn at a peak time of the day, learning at your own speed, accessibility to much information, an ability to track personal progress, and the capability of testing personal learning efforts. In addition, e-learning students are ideally in an environment where professors respond to their needs on demand [19].

However, most learning environments neglect the learning services and pedagogical aspects of e-teaching. Hence, its development has lagged behind the massive investment in hardware and teacher training in using ICT [13]. According to some researchers, e-learning pedagogy should incorporate the learning pedagogy but go beyond it to include a deeper study into the incorporation of instructional strategies that take into account of real-time personalized learning content-to-learner adaptability [26].

In line with this, there is research in the areas of intelligent tutoring systems, virtual mentors, and adaptive hypermedia the techniques and tools that can provide improved learning outcomes [2], [7]. They target and deliver just-in-time learning materials required by the individual learners [6]. According Gregg, software agents can be used to support instructors and domain experts with course design and delivery, as well as individual learners by personalizing course materials based on learning objectives. Pedagogical agents have positive effects on learning and have the following characteristics [18].

- Adaptation: understand the student's needs and adapt the lesson plan.

- Motivation: offer encouragement to the students and give them feedback.

- Evolution: keep students current in a rapidly changing culture.

\section{Developing Digital Skills Through E-Learning}

Research shows that there is a strong relationship between education level and leadership [14]. Leaders have the greatest impact on organizational performance. The success of an organization depends on their skills and abilities [31]. It means many different things to 
educators from primary schools to the university. At each level of education, it is reasonable to expect different outcomes, but the overall purpose remains to develop expertise as an entrepreneur. Higher education is of especially key importance for entrepreneurs. Education, on one hand, encourages entrepreneurship and sets the substructure of entrepreneurship culture; on the other hand, it develops competencies of entrepreneur will need when he sets up a company.

Researchers define leaders and entrepreneurial competency as the ability to interact with the business environment effectively [22], [20]. Competencies consist of knowledge, skills, attitudes, behaviors, and abilities necessary to do a job successfully. They are easily identified and measured. Competencies can be improved through experience, education, and training.

That is to say, while they often learn and gain experience through practice and from their role models in business, without education they will not be able to test their ideas, and education will help them turn those ideas into reality more easily. Besides, education develops the creativity and skills that are important for rapid decision-making in a business environment that is constantly changing. Hence, the education programs for leaders and entrepreneurs can be of relevance to develop their competencies.

\section{Methodology}

The questionnaire was designed to investigate the concepts of "e-learning" / "distance learning" and "entrepreneurship", from the standpoint of view of students in this field. This questionnaire was given to Belgrade Business School, Serbia in 2017. The sample of students who participated in the survey were around 200.

The gender ratio of the respondents was 72:20 (female and men respectively). The highest percentage of women consists of those between 19 to 22 years old.

\section{Research Findings}

About $90 \%$ of the respondents were ready to launch their own businesses as soon as they graduate. The explanation lies in the fact that the respondents attend a business school.

Certainly, the results would be different if the same question were asked to students attending a technical university or college.

For the second question, it was of key importance for respondents to earn more if they work for themselves (45\%). Also, it can be concluded that the most responders did not have a role model among that country's many successful entrepreneurs. The reason that young people in Serbia do not have role models can be explained by the fact that here is a much smaller number of true role models.

The majority of women did not believe that distance learning would be a good solution for future young entrepreneurs. Namely ,almost all respondents said "Yes" Probably, the reason for such a large number of respondents who gave a positive answer can be found in the fact that the students would like to see how e-learning works in practice because it is still not very much applied in Serbia before COVID-19 crisis in 2020.

Regarding question seven, 25\% respondents said that "Acquisition of knowledge" was the most important thing to consider when selecting an e-learning program. The second option, "The faster and easier way to graduate," was chosen by $29 \%$. The third option, "Flexibility in studying," was chosen by $48 \%$ students (Fig. 1). There are no significant differences between respondents divided by gender for this question for both countries. It should be noted that the top priority for respondents from Serbia in selecting an e-learning program was "flexibility in studying," while for those from Turkey, "acquisition of knowledge" was chosen as most important [14]. 


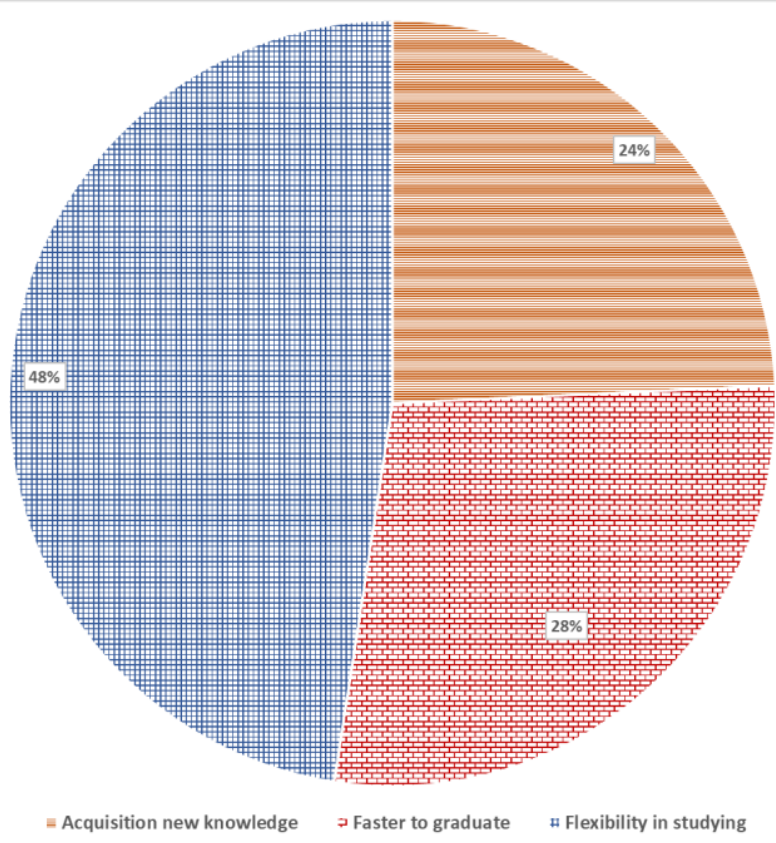

Fig. 1. What would be the most important in selecting such a program, and ways of learning?

For question "What do you think is crucial to be successful in the entrepreneurial career?" the first option "Have the ability to innovate and original business ideas" was selected by $22 \%$ students. The second option, "Having good business contacts," was selected by $70 \%$. The third option, "To be highly motivated to succeed," was selected by 6\% (Fig. 2).

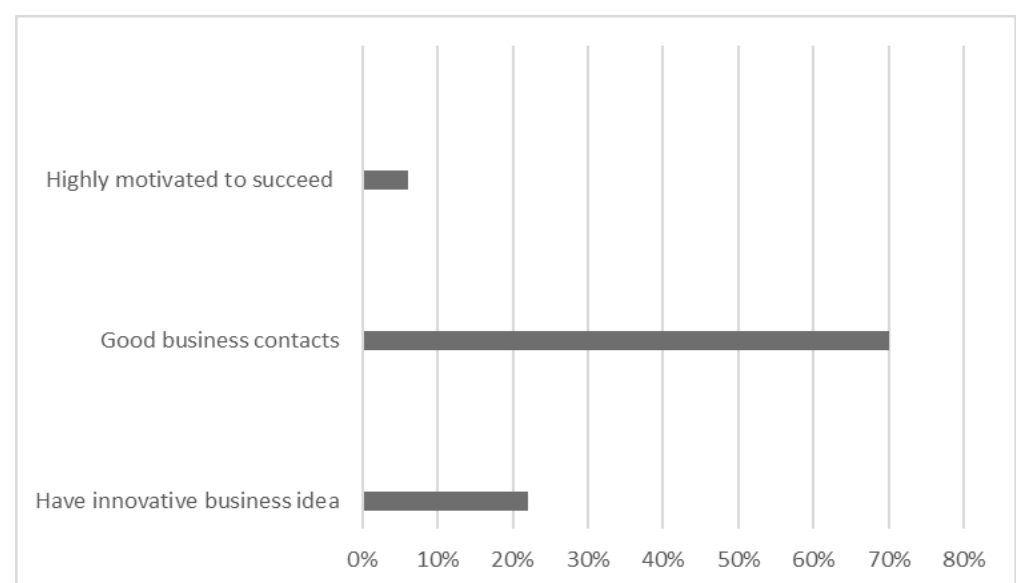

Fig. 2. What do you think is crucial to be successful in an entrepreneurial career?

As many as $90 \%$ of respondents believed that the distance learning would be a good solution for future young entrepreneurs.

Our research shows that education based on freedom in both learning and teaching helps to foster creativity. Accordingly, the existing education system should be redefined as well as educational programs for entrepreneurship [14]. Education represents the "central nervous system" of every society - the pedagogic, educational, cultural chain that constantly vibrates [28].

If Serbians or citizens of other nations become more familiar with the techniques, potential learners as well as educators may be able to effectively discern the pros and cons of how elearning would enhance and improve education [17]. One hopeful sign is that recently a number of studies have been done in Serbia in order to investigate the different aspects of elearning, especially in the field of business and entrepreneurship [18], [17]. Building a more 
inclusive distance learning environment in Serbia involves making technological choices built on flexibility and an ability to respond quickly to changes in constantly evolving technology and informational resources. Collaboration, involving teachers, mentors, and instructional designers who truly represent the hard-to-reach learners, and a willingness to invest monies in developing a cyber-infrastructure that reaches all learners regardless of where they live will be crucial. [16]

\section{Conclusion}

E-learning is now an essential component of education in many countries. It has changed the face of education, training, and vocational learning forever. The online learning environment is quite different from a traditional classroom, in which one had limited interaction and almost unlimited access to learning resources. In other words, online courses require participants to take on new and different teaching and learning behaviors, which are quite different from the old ones. New technologies also can improve communication between students and teachers. They allow each student greater diversity for learning, enhance interactivity between individual students and individual teachers, provide a space for personalized, flexible learning beyond the classroom walls, and allow students to live locally whilst learning globally through the use of external resources accessed via the world wide web. In addition, the use of different learning materials and resources allows students with various principle learning styles to understand information in the most effective way. Also, the use of intelligent agents as a support to online studies intended for entrepreneurs would provide significant resource savings. On one hand, it would allow students an easier access to information and literature, as well as testing their knowledge and ideas. On the other hand, it would reduce teachers' administrative duties, which would be performed by intelligent agents, thus giving them more time to devote to each student individually and develop their potential entrepreneurial ideas, talents, and skills.

In addition, the Internet enhances learning, including such advantages as being able to learn at a peak time of the day, learning at one's own speed, accessibility to much information, the ability to track personal progress, and the capability to test personal learning efforts. The online education also fosters self-motivated education, giving precedence to the autonomy of the learner. This improves access by increasing the number of available courses and thus number of students served.

Finally, with new technologies in hand, the process of learning in the classroom can become significantly richer as students have access to new and different types of information and can combine face-to-face learning with e-learning opportunities. This combination provides them many opportunities to learn more new things in a quite different environment.

According to new terms of learning because COVID-19, these opportunities will be more exploited in Serbia soon.

\section{REFERENCES}

[1] Bowen, Ed. "Intelligent Agents: What They Do and How They're Changing Online Learning." In Proceedings of TELECOOP Conference, 1-31. Estes Park: TELECOOP, 2007.

[2] Brusilovsky, Peter. Adaptive Educational Hypermedia: From Generation to Generation. Athens: University of Athens, 2004.

[3] Croy, Marvin "Distance Education, Individualization, and the Demise of the University." TechnologyIn Society, No. 20 (1998): pp. 317-326.

[4] Charles Graham, Kursat Cagiltay, Byung-Ro Lim, Joni Craner, and Thomas M. Duffy. "Seven Principles of Effective Teaching: A Practical Lens for Evaluating Online Courses." In Technology Source. Chapel Hill: University of North Carolina, 2001. Accessed October 20, 2013.

[5] Draves, William. Teaching Online. River Falls: LERN Books, 2002. Accessed June 21, 2013. 
[6] Gregg, Dawn. “E-learning Agents” The Learning Organization14, No. 4 (2007): pp. 300-312.

[7] Hanks, Steven and Gaylen Chandler. "Funder Competence, the Environment and Venture Performance" Entrepreneurship Theory and Practice 18, No. 3 (1994): pp. 77-89.

[8] Hua-Lin Tsai, Chi-Jen Lee, Wen-Hsi Lydia Hsu, Yu-Hsin Chang. An Adaptive E-Learning System Based on Intelligent Agents in Recent Researches in Applied Computers and Computational Science. Rovaniemi: WSEAS Press, 2012.

[9] Hoben, George, et al., Assessment of Student Learning in an Educational Administration Online Program. New Orleans: American Educational Research Association, 2002.

[10] Lee, Hon Cheung. "The New Era of Televersity and Andraversity in the Campusless Society: The Virtual University and Its Implications in Korea." In Virtual University? Educational Environments of the Future, edited by U. H. J. Molen, pp. 117-31. London: Portland Press.

[11] Liarokapis, Fotis, Anastasios Doulamis, Vassilios Vescoukis (Eds.). Games and Virtual Worlds for Serious Applications. Athens: IEEE, 2011.

[12] McCombs, Barbara L. "Assessing the Role of Educational Technology in the Teaching and Learning Process: A Learner-Centered Perspective”. In the Secretary's Conference on Educational Technology. Denver: University of Denver Research Institute, 2000. Accessed October 27, 2013.

[13] Newton, Len and Laurence Rogers. Teaching Science with ICT. London: Continuum, 2001. Accessed November 15, 2013.

[14] Radović-Marković, Mirjana. "Female Entrepreneurship: Theoretical Background.” Journal of Women's Entrepreneurship and Education 4, no.1-2 (2013): pp. 1-9.

[15] Radović-Marković, Mirjana, et al., (2017), E-LEARNING AS A TOOL FOR EMPOWERING ENTREPRENEUERSHIP, Journal of Women's Entrepreneurship and Education, n. 3-4, pp. 65-72, dec. 2017. ISSN 2406-0674. Available at:

<http://www.library.ien.bg.ac.rs/index.php/jwee/article/view/559>.

[16] Radović-Marković, Mirjana, et al., "Freedom, Individuality and Women's Entrepreneurship Education." In Entrepreneurship Education a Priority for the Higher Education Institutions, edited by Catalin Martin and Elena Druica. Bologna: Medimond, 2012.

[17] Radović-Marković, Mirjana. \& Biljana Spariosu-Bodroski. "Education in Serbia: Inclusive and Elearning Opportunities.” Serbian Journal of Management 5, No. 2 (2010), pp. 271-281.

[18] Radović-Marković, Mirjana. Impact of Globalization on Organizational Culture, Behaviour and Gender Role. Charlotte: IAP, 2011.

[19] Radović-Marković, Mirjana. "Special Benefits of E-learning for Women: Sample of Program Entrepreneurship." In Gender and Informal Economy: Developing Developed and Transition Countries, edited by Priscilla Achakra, pp. 156-166. Lagos: ICEA and Prenticeconsult, 2007.

[20] Radović-Marković, Mirjana, et al., (2017), E-LEARNING AS A TOOL FOR EMPOWERING ENTREPRENEUERSHIP, Journal of Women's Entrepreneurship and Education, n. 3-4, pp. 65-72, dec. 2017. ISSN 2406-0674. Available at:

<http://www.library.ien.bg.ac.rs/index.php/jwee/article/view/559>.

[21] Radovic-Markovic, M. i Markovic, D. (2012), Creative education and new learning as means of encouraging creativity, original thinking and entrepreneurship in monography "Humanities and the Contemporary world”, Montenegrin Academy of Sciences and Arts, Podgorica, Montenegro.

[22] Radović-Marković, M., Tomaš-Miskin, S., Marković, D., (2019). Digitalization and Agility of Enterprises and Banks: IT Competencies of Managers and Virtual Team Members, International Journal of Entrepreneurship, pp. 1-11.

[23] Ruzgar, Nursel. "Distance Education in Turkey." Turkish Online Journal of Distance Education 5, No 2 (2004), pp. 22-32. Accessed on 16 May 2006. http://tojde.anadolu.edu.tr/tojde14/articles/ruzgar.htm.

[24] Spatariu, Alexandru, Kendall Hartley, and Lisa Bendixen. "Defining and Measuring Quality in OnlineDiscussions." The Journal of Interactive Online Learning 2, No. 4 (2004). Available online: http://www.ncolr.org/jiol/archives/2004/spring/02/.

[25] Teo, Chao Boon, Robert Gay, and Kheng Leng. "Pedagogy Considerations for E-learning." International Journal of Instructional Technology and Distance Learning 3, No. 5. (2006): pp. 3-26.

[26] Wagner, Thomas. Applying Agents for Engineering of Industrial Automation Systems. Stuttgart: Universität Stuttgart, 2003.

[27] Sormaz G., Andjelic S., Markovic Blagojevic M. (2019) Odredjenje savremenog menadžmenta u obrazovanju, Trendovi u poslovanju godina VII, broj 13, sveska 1/2019, pp. 11-18.

[28] Cukanović Karavidic M., Karavidic S., Vujicic S. (2016), "Business education and social skills to leadership competencies", International Review, No. 1-2/2016, Faculty of Business Economics and Entrepreneurship, Belgrade, ISSN 2217-9739, pp. 38-45.

[29] Sokolov Milovancevic N., Kitic A. (2019) "Leadreship in Serbian healthcare system” EKONOMIKA, ISSN 0350-137X, Društvo ekonomista, Ekonomika, Niš, Vol. 65, No. 1, pp. 57-65 
[30] Marjanović N., Jovanović J., Ratknić T., Paunković Dž. (2019) The role of leadership in natural resource conservation and sustainable development: A case study of local self-government of Eastern Serbia, Ekonomika poljoprivrede, vol. 66, iss. 3, pp. 889-903, 2019.

\section{Article history:}

Received 25 May 2020

Accepted 28 Juny 2020 